\title{
INVESTIGATION OF POLAR SURFACE AREA AS A NOVEL PARAMETER AFFECTING ORAL BIOAVAILABILITY OF DRUGS
}

\author{
Mohammed A. Osman ${ }^{1}$, Gamal M. El Maghraby ${ }^{1 *}$ and Mohsen A. Hedaya ${ }^{2}$ \\ ${ }^{1}$ Department of Pharmaceutical Technology and ${ }^{2}$ Department of Clinical Pharmacy, \\ College of Pharmacy, Tanta University, Tanta, Egypt
}

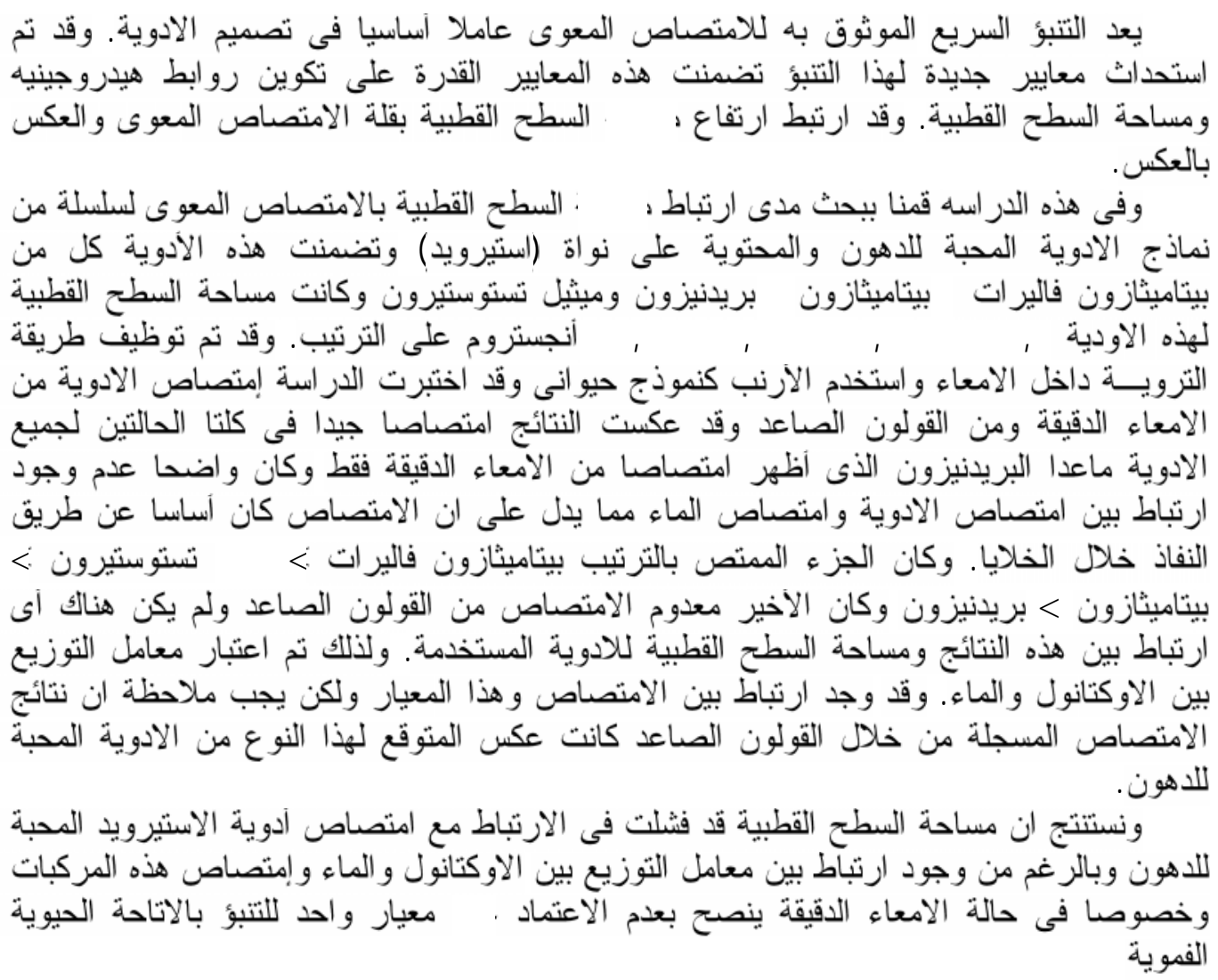

Fast and reliable prediction of intestinal absorption is a key factor in drug design. New parameters for this prediction have been introduced recently. These included the hydrogen bonding capacity and the polar surface area (PSA). High PSA accounted for poor oral absorption and vice versa. Here we are investigating the significance of PSA in intestinal absorption of a series of lipophilic steroidal model drugs. These included; Betamethason valerate (BMV), Betamethasone (BM), prednisone (PD) and methyltestosterone (MT), with PSA values of 100.9, 94.83, 91.67 and $37.3 \AA$, respectively. An in situ intestinal perfusion technique was employed using the rabbit as model animal. The study investigated drug absorption from the jejunoileum and ascending colon. The results revealed good absorption from both segments for all tested drugs except PD which was absorbed from the jejunoileum only. Poor correlation was evident between the absorptive clearance and the net water flux in both segments suggesting mainly a trans-cellular absorption of these compounds. The percentage fraction absorbed (\%Fa) was in the order of $B M V>M T>B M>P D$ with the later showing negligible absorption from the ascending colon. These results did not correlate with the calculated PSA values. Accordingly, the octanol/water partition coefficient $(\log P)$ was considered. The $\log P$ values were, 3.6, 3.36, 1.94 and 1.46 for BMV, MT, BM and PD, respectively. These values correlated with the \%Fa values. However, it should be noted that the recorded colonic absorption is against expectation for such lipophilic drugs. In conclusion PSA failed to 
correlate with the oral absorption of the lipophilic steroids. Although log P correlated well with the absorption of these compounds especially with jejunoileum segment it is advisable not to rely on single factor for predicting oral bioavailability.

\section{INTRODUCTION}

Fast and reliable prediction of intestinal absorption is a key factor in drug design. The octanol/water partition coefficient (PC) is the most frequently used parameter for this purpose. New parameters have been adopted recently. These included the hydrogen bonding capacity and the Polar Surface Area (PSA). ${ }^{1-4}$ High PSA accounts for poor oral absorption and vice versa. PSA was also employed to predict drug penetration through the blood brain barrier. ${ }^{5}$ In contrast to intestinal mucosa and blood brain barrier, the pulmonary epithelium was reported to be highly permeable to compounds with high PSA. ${ }^{6}$

The intestinal absorption of xenobiotics could be examined at different levels of integration, in whole animal in vivo, employing isolated intestinal segments in situ and in intestinal loops or using enterocytes in vitro. ${ }^{7}$ The in situ methods have the advantage of bypassing the effect of food, drug dissolution and stomach emptying steps after oral dosing. They also allow the researcher to control the input and to select the perfused intestinal segment. In addition, the in situ methods provide intact lymph, blood and nerve supply for the solute uptake with extended tissue viability demonstrating superiority over in vitro methods. One of these in situ techniques "through-and-through" intestinal perfusion has been employed to monitor the absorption of several compounds, using rabbit as the model animal. ${ }^{8-10}$ Accordingly we selected the through-and-through technique to investigate the absorption of the series of model steroidal drugs from two different segments of the intestine.

The current study investigated the correlation of PSA with the intestinal absorption of a series of steroidal model drugs. PC was also considered and correlated with the oral absorption of the model drugs. The selected model drugs included; Betamethason valerate (BMV), Betamethasone (BM), prednisone (PD) and methyltestosterone (MT), which cover a wide range of PSA values. The calculated PSA values were 100.9, 94.83, 91.67 and $37.3 \AA$ for the selected model drugs, respectively. The chemical structure of these drugs is presented in Figure 1.

The drug absorption was studied at two different anatomical sites in the rabbit intestine, namely the jejunoileum and the ascending colon. The rabbit was selected as the model animal as it has intestinal physiology similar to that of human. ${ }^{11-13}$

\section{MATERIALS AND METHODS}

\section{A- Materials}

Betamethason valerate (BMV), prednisone (PD) and methyltestosterone (MT) were obtained from Schering AG Berlin, Germany. Betamethasone (BM) was from Memphis Co. for pharmaceutical and chemical industeries, Cairo, Egypt. Methanol and acetonitrile (HPLC - grade) were obtained from BDH, England. Sodium chloride $0.9 \%$ for injection, USP was obtained from El-Nasr Pharmaceutical Chemicals Company, Egypt. Ketamine $\mathrm{HCl}$ $(100 \mathrm{mg} / \mathrm{ml})$ was obtained from EIPICO Pharmaceutical Company, Egypt. Chlorpromazine $\mathrm{HCl}(25 \mathrm{mg} / \mathrm{ml})$ was obtained from Misr Pharmaceuticals Company, Egypt.

\section{B- Calculation of PSA}

PSA was calculated using the fragment based contribution. ${ }^{14}$ The chemical structures, the calculated PSA values of the model drugs are presented Figure 1.

\section{C- Preparation of the perfusion solutions}

The perfusion solutions containing equimolar concentration $(0.03 \mathrm{mM})$ of the tested drugs were separately prepared in $0.9 \%$ w/v sodium chloride for injection, USP. This required bath sonication and heating. The perfusion solutions were maintained at $37^{\circ}$ throughout the experiment.

\section{D- Segment preparation}

Male albino rabbits weighing $2.8-3.1 \mathrm{~kg}$ were used. Prior to surgery, the rabbit was fasted over night. The animal was anesthetized 
<smiles>CCCCC(=O)O[C@]1(C(=O)CO)[C@@H](C)CC2C3CCC4=CC(=O)C=C[C@]4(C)[C@@]3(C)C(O)C[C@]21C</smiles>

Betamethasone Valerate

PSA $=100.9$

$\mathrm{PC}(\log \mathrm{P})=3.6$

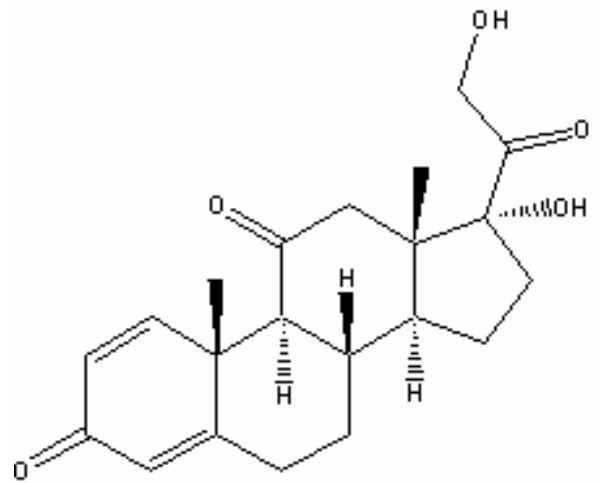

Prednisone

$\mathrm{PSA}=91.67$

$\mathrm{PC}(\log \mathrm{P})=1.46$



Betamethasone

PSA $=94.83$

$\mathrm{PC}(\log \mathrm{P})=1.94$

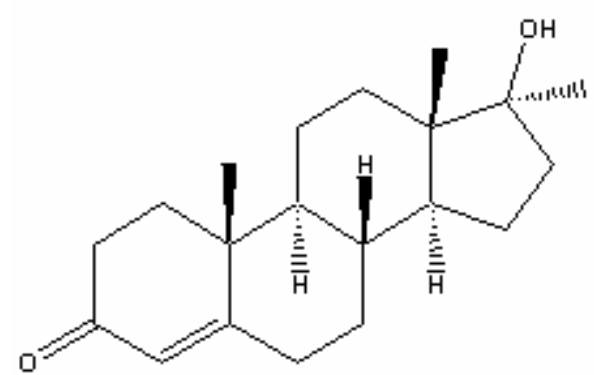

Methyltestosterone

$\mathrm{PSA}=37.3$

$\mathrm{PC}(\log \mathrm{P})=3.36$

Fig. 1: Chemical structure, polar surface area (PSA) and partition coefficient (PC) of the tested drugs.

by deep and rapid intramuscular injections of ketamine $\mathrm{HCl}$, given in two doses each of 45 $\mathrm{mg} / \mathrm{kg}$ at 15 minutes interval and when necessary a third dose of $25 \mathrm{mg} / \mathrm{kg}$ was injected 15 minutes later. Chloropromazine $\mathrm{HCl}$ was used as muscle relaxant (two doses of $2 \mathrm{mg} / \mathrm{kg}$ given I.m at $15 \mathrm{~min}$ interval, given before the anesthetic).

After induction of anesthesia the rabbit was laid in a supine position on an underpad, which was placed over a heating pad to maintain body temperature throughout the experiment. The abdominal area was shaved and cleaned before making a longitudinal incision of $6-8 \mathrm{~cm}$. The intestinal segments of interest were exposed and isolated carefully. In order to cannulate the jejunoileum segment, the proximal end was tied off using surgical silk before being cannulated with a 3-way stopcock cannula. The desired length $(30 \mathrm{~cm})$ was then measured by a premeasured thread, and the distal end was cannulated using an L-shaped glass cannula. This was cleaned by perfusing warm normal saline $\left(37^{\circ}\right)$ through the segment. For the colon, the proximal end was tied off immediately after the ampulla coli, the desired length $(15 \mathrm{~cm})$ was measured adopting the same procedures, and finally the distal end tied off. Two incisions were made, one on each end, and the solid fecal debris was squeezed out by gentle manipulation of the segment. The rest of the fecal debris was removed by gently infusing warm normal saline $\left(37^{\circ}\right)$ through the proximal end. Finally, both the proximal and distal ends were cannulated as described before. Any washing fluid was removed from both segments by slowly pumping air through them, followed by evacuation by gently pressing the segments with the finger tips. 
The intestinal segment under study was carefully arranged in a uniform S- to multi-Spattern, depending upon the length, to avoid kinks and ensure uniformity in the intestinal fluid flow during perfusion. The isolated segment was kept warm and moist by frequent application of warm normal saline $\left(37^{\circ}\right)$ to a gauze pad covering the intestine. The isolated segments were kept in a horizontal level throughout the experiment to avoid the hydrostatic pressure which could affect the fluid movement across the intestinal membrane. At the end of the experiment the animal was euthanized by injecting an overdose of sodium pentobarbital through the marginal ear vein. The intestinal segments under study were excised and an exact measure of the length of these segments was done by placing each segment on a ruler wetted with normal saline. This length was used for estimation of the membrane transport parameters. ${ }^{8}$

\section{E- In Situ intestinal perfusion}

Solutions containing the tested drugs in normal saline, as described before were separately perfused at a flow rate of 0.27 $\mathrm{ml} / \mathrm{min}$ using a peristaltic pump (LKB Produkter AB S-16125 Bromma, Sweden). The time at which the perfusate started to flow from the distal end was taken as the lag time. After the lag time, the intestinal effluent samples were collected at 10-minutes intervals for 120 minutes in 10-ml pre-weighed stoppered tubes. These tubes were weighed again after sample collection, and the effluent weight was recorded as the difference. Intestinal net water flux was estimated gravimetrically and the effluent concentrations were corrected accordingly. To monitor the drug stability in the perfusion solution the perfusate was sampled at zero time and at the end of the experiment. All samples were analyzed using HPLC as described below.

The current study utilized 12 rabbits divided into 4 groups. Each group was employed to investigate the intestinal absorption of a model drug.

\section{F- Chromatography}

The drug concentrations in all samples were determined using an HPLC analysis. This employed a high pressure liquid chromatograph (Waters ${ }^{\mathrm{TM}} 600$ controller, USA) equipped with a variable wavelength detector (Waters ${ }^{\mathrm{TM}} 486$, Tunable Absorbance Detector, USA) and an automatic sampling system (Waters ${ }^{\mathrm{TM}} 717$ Plus Autosampler, USA). This was under computer control. Separation was accomplished on a reversed phase column $15 \mathrm{~cm} \mathrm{X} 3.9 \mathrm{~mm}$ (i.d.) $\mathrm{C}_{18}, \mu$ Bondapak $^{\mathrm{TM}}$, Waters, with an average particle size of $10 \mu \mathrm{m}$.

The mobile phase was a mixture of methanol, acetonitril and water (50:8:42) flowing at $1.2 \mathrm{ml} / \mathrm{min}$, with propylparaben employed as internal standard in case of prednisone which was detected at $238 \mathrm{~nm}$. A representative chromatogram is presented in Figure 2 for prednisone with its internal standard. For the other drugs (BMV, BM and MT) detection was at $242 \mathrm{~nm}$ and the mobile phase was a mixture of methanol, acetonitril and water (50:15:35). The flow rate was 1.2 $\mathrm{ml} / \mathrm{min}$, at ambient temperature. Since the last three compounds were analyzed using the same chromatographic conditions, MT was used as the internal standard for BMV and BM while BMV was used as the internal standard for MT. A representative chromatogram is presented in Figure 3 showing BM, MT, BMV appearing on the same chromatogram.

The perfusate samples collected during the intestinal perfusion were centrifuged for 5 minutes in order to precipitate any mucus debris. These were diluted 1 in 2 with mobile phase before addition to test tubes spiked with the corresponding internal standard. The tubes were vortex mixed for 1 minute before loading into the HPLC vials and injecting $30 \mu \mathrm{l}$ into the HPLC.

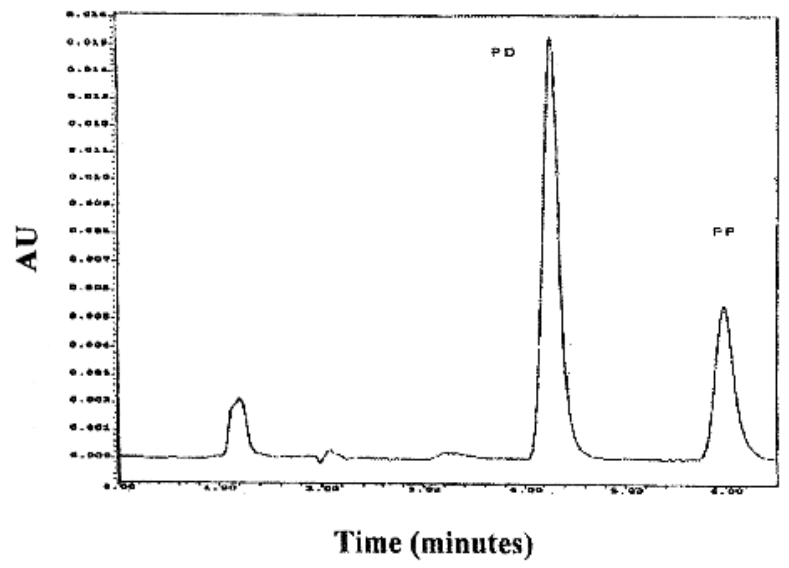

Fig. 2: A representative HPLC chromatogram of prednisone (PD) and its internal standard (propylparaben, PP). 


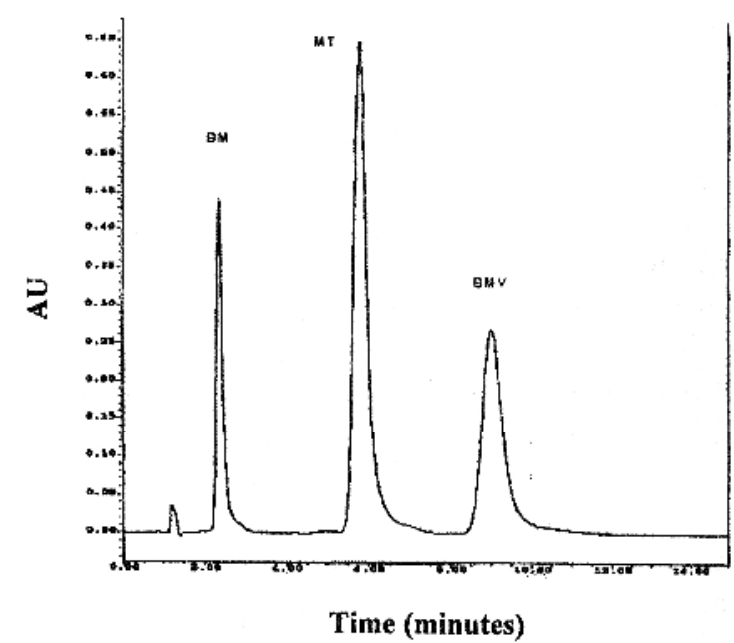

Fig. 3: A representative HPLC chromatogram showing betamethasone (BM), methyltestosterone (MT) and betamethasone valerate (BMV).

\section{G- Data analysis \\ I- Absorptive clearance}

The flow rate was estimated for each perfusion experiment from the linear regression of the volume remaining in the perfusion syringe versus time. The volume of the outflow samples was estimated gravimetrically taking the density of the aqueous samples as 1 (the same as water). From the difference in flow rate entering and leaving the intestinal segment, the outflow concentration was corrected for the net water flux. The ratio between the corrected concentration at the outflow $\left\{\mathrm{C}_{\text {(out) }}\right\}$ and that at the inflow $\left\{\mathrm{C}_{(\mathrm{in})}\right\}$ was calculated for each perfusate sample collected. The average of the outflow-to-inflow concentration ratios for the fractions collected from 70 to $120 \mathrm{~min}$ was taken as the steady-state ratio. This ratio at steady-state is given by: ${ }^{8,15-19}$

$\left\{\mathrm{C}_{\text {(out) }} / \mathrm{C}_{\text {(in) }}\right\}_{\mathrm{ss}}=\exp ^{-(\mathrm{PeA} / \mathrm{Q})}$

where $\mathrm{A}$ is the effective surface area $\left(\mathrm{cm}^{2}\right), \mathrm{Pe}$ is the apparent permeability coefficient $(\mathrm{cm} / \mathrm{min})$, and $\mathrm{Q}$ is the average flow rate within the intestinal segment $(\mathrm{ml} / \mathrm{min})$. Rearrangement of equation (1) allows the permeability-area product $(\mathrm{PeA})$ to be calculated:

$\mathrm{Pe} A=-\mathrm{Q} \cdot \ln \left(\mathrm{C}_{\text {(out) }} / \mathrm{C}_{\text {(in })}\right)_{\mathrm{ss}}$

Employing in situ intestinal perfusion technique, the term (PeA) should be normalized to the length of the intestinal segment in order to allow for comparison of the effective permeability of segments having different lengths.

Since $\left\{\mathrm{C}_{\text {(out) }} /\left(\mathrm{C}_{\text {(in) }}\right)\right\}_{\text {ss }}$ is the fraction remaining after solution has passed through the intestinal length, then the fraction absorbed is:

$\mathrm{Fa}=1-\left\{\left(\mathrm{C}_{(\text {out }}\right) /\left(\mathrm{C}_{(\text {in })}\right)\right\}_{\mathrm{ss}}=1-\exp ^{-(\mathrm{Pe} A / \mathrm{Q})}$

Associated with the concept of intestinal absorption is the reserve length, ${ }^{8,17}$ the anatomical reserve length (ARL), is defined as the length of the intestine remaining after absorption has been completed, and it is given by:

$\mathrm{ARL}=\left(\mathrm{L}^{*}\right)-\left(1^{*}\right)$

where, ARL is the anatomical reserve length $(\mathrm{cm}) . \mathrm{L}^{*}$ is the maximal intestinal length available for absorption. $1^{*}$ is the intestinal length along which absorption is complete, (cm). In theory, the bulk luminal concentration will never be reduced to zero at the intestinal length $\left(1^{*}\right)$, due to the nature of the logarithmic function. Accordingly, an arbitrary small fraction of solute remaining will be considered as the criteria for complete absorption. Taking this fraction as 5\%, and replacing in equation (1) will give the following:

$0.05=\exp ^{-\left\{\left(\text {PeA. } I^{*}\right) / Q\right\}}$

where, PeA is the effective permeability surface area product normalized to length. $1^{*}$ is the length required for 95\% absorption (L95\% ab.) of a given solute.

\section{II- Effect of solvent drag on intestinal absorptive clearance}

The influence of water flux on the absorption of the drugs across the intestinal membrane was studied by plotting the absorptive clearance versus the net water flux $\mathbf{J}_{\mathrm{w}}$, where $\mathbf{J}_{\mathrm{w}}(\mathrm{ml} / \mathrm{min})$ is given by:

$\mathrm{J}_{\mathrm{w}}=\mathrm{Q}_{\text {(in) }}-\mathrm{Q}_{\text {(out) }}$

where $\mathrm{Q}_{\text {(in) }}$ is the flow rate entering the intestinal segment and $\mathrm{Q}_{(\text {out }}$ is the flow rate leaving it. The net amount of drug absorbed per unit time can be described as the sum of two terms; the diffusive contribution and the convective contribution corresponding to the solvent drag effect. The net amount of drug absorbed per unit time is then given by the following equation. ${ }^{8}$ 
$J_{s}=K s\left(C-C_{p}\right)+\varnothing s_{s} C$

In which the first term on the right is diffusive and the second is convective and Js is the rate of absorption of the solute from the lumen $(\mu \mathrm{g} / \mathrm{min})$ and is given by $\Delta \mathrm{Ns} / \Delta \mathrm{t}$ where, $\Delta \mathrm{Ns}$ is the amount of the solute $(\mu \mathrm{g})$ absorbed in a time interval $\Delta \mathrm{t}(\mathrm{min})$. Ks is the diffusive permeability coefficient and is given by DAKp/ $\Delta \mathrm{x}$, in which $\mathrm{D}$ is the diffusion coefficient of the solute, $\mathrm{A}$ is the effective surface area, $\mathrm{Kp}$ is the partition coefficient of the compound, and $\Delta \mathrm{x}$ is the path length. $\mathrm{C}$ and $\mathrm{C}_{\mathrm{p}}$ are the solute concentrations in the lumen and plasma, respectively. $\varnothing \mathrm{s}$, is the sieving coefficient of the given compound, represents the ratio between the concentration of the compound in the convective stream to that in the luminal fluid, $\varnothing$ s equals $1-\sigma$, where $\sigma$, is Staverman reflection coefficient of a given compound, represents its interaction with water. Jw is the rate of fluid (or water) flux without reference to its mechanism (osmotic, hydrostatic or electrical). The water flux is absorptionsecretion process which is dependent on the experimental parameters during the perfusion. $\mathrm{Jw}, \mathrm{Ks}$, and $\varnothing_{\mathrm{s}}$ are assumed to remain constant during a given experiment run. At the steady state, due to sink conditions in the blood, equation (7) is reduced to

$\mathrm{J}_{\mathrm{ss}}=\mathrm{DAKp} / \Delta \mathrm{x}\left(\mathrm{C}_{\mathrm{ss}}\right)+\varnothing \mathrm{Jw}\left(\mathrm{C}_{\mathrm{ss}}\right)$

where, $\mathrm{J}_{\mathrm{ss}}$ is the steady state solute flux $(\mu \mathrm{g} / \mathrm{min})$ and $\mathrm{C}_{\mathrm{ss}}$ is the length averaged steady state concentration of the solute in the lumen $(\mu \mathrm{g} / \mathrm{ml})$.

Rearrangement of equation (8) gives the following equation:

$\mathrm{J}_{\mathrm{ss}} / \mathrm{C}_{\mathrm{ss}}=\mathrm{DAKp} / \Delta \mathrm{x}+\varnothing \mathrm{JW}$

The term $\mathrm{J}_{\mathrm{ss}} / \mathrm{C}_{\mathrm{ss}}$ represents the overall absorptive clearance of the given solute $(\mathrm{ml} / \mathrm{min})$, regardless its route or mechanism, and practically it is estimated as the overall absorptive clearance, (PeA), (equation 2).

\section{RESULTS AND DISCUSSION}

\section{Intestinal permeability of methyltesto- sterone (MT)}

The membrane transport parameters of the tested drugs through the jejunoileum and the colon are presented in Tables 1 and 2. MT has the smallest PSA values among the tested drugs $(37.3 \AA)$, indicating low hydrogen bonding capacity, high lipophilicity and thus good absorption. It has a $\log \mathrm{P}$ value of $3.36 .^{20}$ The membrane transport parameters through the jejunoileum (Table 1) revealed good absorption from this segment. The fraction absorbed was $89.35 \%$. The length of the jejunoileum required for $95 \%$ absorption of MT was $45.5 \mathrm{~cm}$ and the fraction remaining for absorption was relatively small (0.1065). The parameters for colonic absorption of MT revealed high absorption (Table 2). The fraction absorbed was $81.73 \%$. Only $17.82 \mathrm{~cm}$ were required for $95 \%$ absorption and the fraction remaining for absorption was 0.1823 .

To probe the site dependent absorptive clearance of MT, the absorptive clearance normalized to the segment length $(\mathrm{PeA} / \mathrm{L})$ was considered for jejunoileum and the colon. It was found to be 0.0229 and $0.0579 \mathrm{ml} / \mathrm{min} . \mathrm{cm}$ for jejunoileum and colon, respectively. This length normalized intestinal absorption was greater in the colon compared with that in the jejunoileum (Student's t test, $\mathrm{P}<0.05$ ). This is against expectation for a nonpolar drug like MT. In agreement with this results MT was reported to have $\mathrm{T}_{\max }$ of 8.8 hours in trout, indicating delayed absorption peak from lower parts of the intestine. ${ }^{21}$

To investigate the mechanism of intestinal absorption of MT, the dependence of the absorptive clearance on the net water flux was monitored in the jejunoileum and the colon. The permeability surface area product at the steady state $(\mathrm{PeA})$ is plotted against the net water flux (JW) for MT in the jejunoileum and the colon. This is shown in Figure 4. The data were fitted to equation 9 by linear regression. The regression parameters are presented in Table 3 for both segments with all tested drugs. The intercept of the regression line produces the transcellular permeability coefficient $(\mathrm{DAKp} / \Delta \mathrm{x})$ and the slope of the regression line gives the sieving coefficient $(\varnothing \mathrm{s})$ which correlates with the paracellular absorption. For MT the intercept was significantly different from zero in case of the jejunoileum and the colon $(\mathrm{P}<0.01)$. However, slope was not significantly different from zero in both the jejunoileum and the colon (Table 3). These results demonstrated mainly transcellular 
Table 1: Membrane transport parameters of the tested drugs through the jejunoileum.

\begin{tabular}{|c|c|c|c|c||}
\hline Parameter & Methyltestosterone & Prednisone & Betamethasone & $\begin{array}{c}\text { Betamethasone } \\
\text { Valerate }\end{array}$ \\
\hline $\begin{array}{c}\text { PeA } \\
(\mathrm{ml} / \mathrm{min})\end{array}$ & 0.8250 & 0.1636 & 0.2892 & 1.316 \\
$(0.0108)$ & $(0.0251)$ & $(0.110)$ & $(0.114)$ \\
\hline \multirow{2}{*}{ Rout/Rin } & 0.1065 & 0.5430 & 0.411 & $0.0253(0.0054)$ \\
& $(0.00863)$ & $(0.0677)$ & $(0.147)$ & 97.46 \\
$\% \mathrm{Fa}$ & 89.35 & 45.68 & 58.82 & $(0.546)$ \\
\hline $\mathrm{PeA} / \mathrm{L}$ & $(0.863)$ & $(6.77)$ & $(14.7)$ & 0.0429 \\
$(\mathrm{ml} / \mathrm{min} . \mathrm{cm})$ & $(0.00027)$ & $(0.00076)$ & $(0.00229)$ & $(0.003)$ \\
\hline $1^{*}(\mathrm{~L} 95 \%)$ & 45.50 & 206.7 & 116.5 & 23.43 \\
$(\mathrm{~cm})$ & $(6.16)$ & $(59.57)$ & $(37.69)$ & $(1.073)$ \\
\hline $\mathrm{JW}$ & -0.0924 & 0.0763 & 0.0072 & -0.0340 \\
$(\mathrm{ml} / \mathrm{min})$ & $(0.0979)$ & $(0.0296)$ & $(0.0069)$ & $(0.0502)$ \\
\hline
\end{tabular}

Where PeA is the overall absorptive clearance, Rout/Rin is the fraction remaining to be absorbed, \% Fa is the percentage fraction absorbed, $\mathrm{PeA} / \mathrm{L}$ is the effective permeability surface area product normalized to the segment length , L95\% is the length required for $95 \%$ absorption and JW is the water flux. Values between brackets are $\mathrm{SD}, \mathrm{n}=3$.

Table 2: Membrane transport parameters of the tested drugs through the colon.

\begin{tabular}{|c|c|c|c|c|}
\hline Parameter & Methyltestosterone & Prednisone & Betamethasone & $\begin{array}{c}\text { Betamethasone } \\
\text { Valerate }\end{array}$ \\
\hline $\begin{array}{c}\text { PeA } \\
(\mathrm{ml} / \mathrm{min})\end{array}$ & 0.5795 & -0.0387 & 0.1668 & 1.363 \\
\hline \multirow{2}{*}{ Rout/Rin } & $0.149)$ & $(0.0285)$ & $(0.0878)$ & $(0.0337)$ \\
\hline \multirow{2}{*}{$\% \mathrm{Fa}$} & $(0.0796)$ & 1.141 & 0.5159 & 0.0175 \\
& 81.73 & -14.06 & 48.41 & $9.00355)$ \\
\hline $\mathrm{PeA} / \mathrm{L}$ & $(7.92)$ & $(10.29)$ & $(10.38)$ & $(0.357)$ \\
$(\mathrm{ml} / \mathrm{min} . \mathrm{cm})$ & $(0.0149)$ & -0.00327 & 0.01857 & 0.1279 \\
\hline $\mathrm{L}^{*}(\mathrm{~L} 95 \%)$ & 17.82 & -287.6 & 74.12 & $(0.00437)$ \\
$(\mathrm{cm})$ & $(4.78)$ & $(114.3)$ & $(55.4)$ & $(0.568$ \\
\hline $\mathrm{JW}$ & -0.0274 & -0.00833 & 0.0489 & -0.0130 \\
$(\mathrm{ml} / \mathrm{min})$ & $(0.0461)$ & $(0.00152)$ & $(0.0365)$ & $(0.0139)$ \\
\hline
\end{tabular}

Where PeA is the overall absorptive clearance, Rout/Rin is the fraction remaining to be absorbed, \% Fa is the percentage fraction absorbed, $\mathrm{PeA} / \mathrm{L}$ is the effective permeability surface area product normalized to the segment length , L95\% is the length required for $95 \%$ absorption and JW is the water flux. Values between brackets are $\mathrm{SD}, \mathrm{n}=3$. 
Table 3: Effect of water flux $(\mathrm{ml} / \mathrm{min})$ on the overall absorptive clearance $(\mathrm{ml} / \mathrm{min})$ of the model drugs. Regression parameters are obtained from data to fitting equation 9.

\begin{tabular}{|c|c|c|c|c|}
\hline \multirow{2}{*}{ Drug } & \multicolumn{2}{|c|}{ Intercept $(\mathrm{DAKp} / \Delta \mathrm{x})$} & \multicolumn{2}{|c|}{ Slope $(\varnothing s)$} \\
\hline & Jejunoileum & Colon & Jejunoileum & Colon \\
\hline Methyltestosterone & $\begin{array}{c}0.8149 * * * \\
(0.0254)\end{array}$ & $\begin{array}{c}0.5560 * * * \\
(0.0478)\end{array}$ & $\begin{array}{c}-0.1095^{*} \\
(0.203) \\
\end{array}$ & $\begin{array}{c}-0.4610^{*} \\
(0.652) \\
\end{array}$ \\
\hline Prednisone & $\begin{array}{c}0.0839 * * * \\
(0.0190)\end{array}$ & $\begin{array}{l}-0.0234 * \\
(0.0113)\end{array}$ & $\begin{array}{c}1.043 * * * \\
(0.222)\end{array}$ & $\begin{array}{c}0.8260 * * \\
(0.371)\end{array}$ \\
\hline Betamethasone & $\begin{array}{c}0.2972 * * * \\
(0.0256)\end{array}$ & $\begin{array}{c}0.1360 * * * \\
(0.0304)\end{array}$ & $\begin{array}{l}-1.110^{*} \\
(0.935)\end{array}$ & $\begin{array}{c}0.6325^{*} \\
(0.432)\end{array}$ \\
\hline $\begin{array}{l}\text { Betamethasone } \\
\text { valerate }\end{array}$ & $\begin{array}{l}1.340 * * * \\
(0.0793)\end{array}$ & $\begin{array}{l}1.360 * * * \\
(0.0744)\end{array}$ & $\begin{array}{l}0.6600^{*} \\
(0.990)\end{array}$ & $\begin{array}{c}-0.6260^{*} \\
(1.37)\end{array}$ \\
\hline
\end{tabular}

Values in parentheses are the standard error values, $\mathrm{n}=3$ for each segment. $*$ Not significantly different from zero $(\mathrm{P}>0.05)$. ** Significantly different from zero $(\mathrm{P}<0.05)$. *** Significantly different from zero $(\mathrm{P}<0.01)$. (DAKp/ $\Delta \mathrm{x})$ is the permeability coefficient and $(\varnothing \mathrm{s})$ is the sieving coefficient.
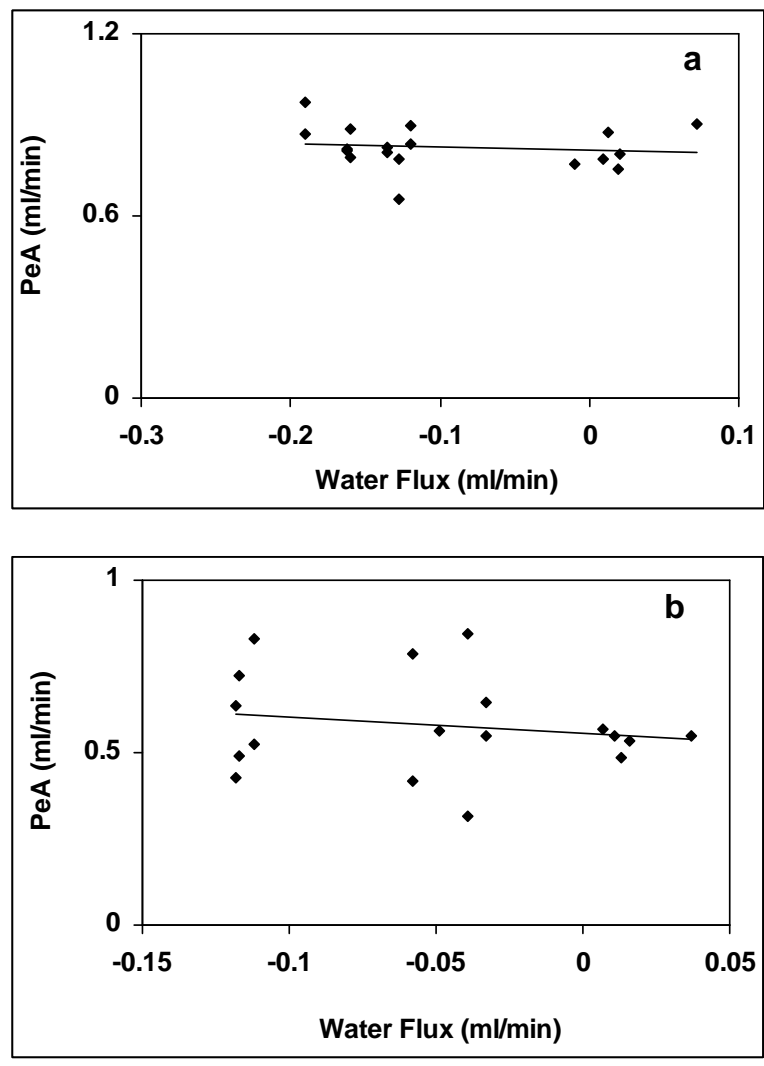

Fig. 4: Absorptive clearance versus water flux of methyltestosterone; (a) jejunoileum and (b) colon.

absorption of MT from both the jejunoileum and the colon with no evidence for paracellular absorption. Colonic absorption was reported for the lipophilic carbamazepine but the paracellular absorption was evident from the colon. $^{8}$

\section{Intestinal permeability of prednisone (PD)}

PD has a PSA value of $91.67 \AA$, which is greater than that of MT. This suggests higher hydrogen bonding capacity, lower lipophilicity and thus lower intestinal absorption compared with MT. It has a $\log \mathrm{P}$ value of $1.46 .^{20}$ The data of PD absorption through the jejunoileum segment (Table 1) revealed low bioavailability. The fraction of the drug absorbed $(\% \mathrm{Fa})$ was $45.68 \%$. The fraction remaining for absorption was 0.543. The theoretical length of this segment corresponding for $95 \%$ absorption of PD was $206.7 \mathrm{~cm}$. The colonic absorption of PD was negligible as indicated by the data in Table 2 which indicate no absorption from the colon. The fraction remaining for absorption was above one indicating no absorption. The data directly indicates that the absorption of PD is mainly from the jejunoileum segment with no expected absorption from the lower parts of the intestine. This data confirms the reported publications citing short time required to reach the peak plasma level $\left(\mathrm{T}_{\max }\right)$ of PD after oral administration with the liquid formulations producing shorter $\mathrm{T}_{\max }$ compared with tablets. Also the reported oral bioavailability was $62 \% .^{22-24}$

To investigate the mechanism of intestinal absorption of PD, the permeability surface area product at the steady state $(\mathrm{PeA})$ is plotted 
against the net water flux (JW) for PD in the jejunoileum and the colon (Figure 5). The regression parameters obtained from Figure 5 and presented in Table 3 revealed that both the intercept and the slope were significantly different from zero for PD absorption form the jejunoileum $(\mathrm{P}<0.01)$. This indicates that the absorption of PD is a combination of transcellular and paracellular. There was a correlation between PD absorption and the net water flux through the jejunoileum. This may suggest some colonic absorption for PD. However, the data revealed negative water flux through the colon indicating water secretion rather than water absorption from the colon in presence of PD. This may be due to a possibly high osmolarity created by PD in solution. The net result was no colonic absorption of PD.
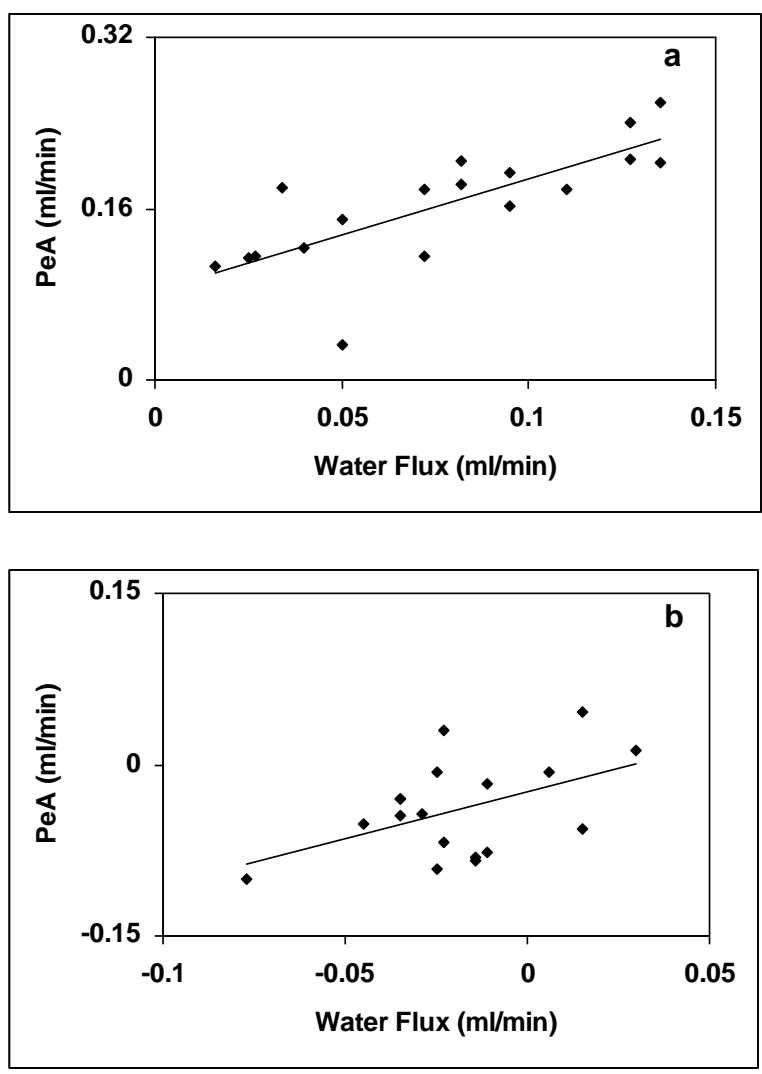

Fig. 5: Absorptive clearance versus water flux of prednisone; (a) jejunoileum and (b) colon.

\section{Intestinal permeability of betamethasone (BM)}

BM has a PSA value of $94.83 \AA$, which is slightly greater than that of PD. This suggests higher hydrogen bonding capacity, lower lipophilicity and possibly lower intestinal absorption. However, the presence of flouride atom in the structure of $\mathrm{BM}$ will add more to the lipophilicity with no contribution to the PSA. Accordingly, the $\log \mathrm{P}$ value of BM was 1.94 which is greater than that of PD. The membrane transport parameters of $\mathrm{BM}$ trough the jejunoileum (Table 1) revealed higher bioavailability values compared with PD but lower than that of MT. The fraction of the drug absorbed was $58.82 \%$ and the fraction of the drug remaining for absorption was 0.411 . The L95\% value was $116.5 \mathrm{~cm}$. The data in Table 2 indicated that unlike PD which had no colonic absorption BM showed significant absorption from the colon. The fraction of BM absorbed from the colon was $48.41 \%$ and the fraction remaining for absorption was only 0.5159 . The L95\% was $74.12 \mathrm{~cm}$.

To research the site dependent absorptive clearance of $\mathrm{BM}$, the length normalized absorptive clearance $(\mathrm{PeA} / \mathrm{L})$ was considered for jejunoileum and the colon. It was found to be 0.0084 and $0.01857 \mathrm{ml} / \mathrm{min} . \mathrm{cm}$ for jejunoileum and colon, respectively. However, the difference was not statistically significant (Student`s t test, $\mathrm{P}>0.05$ ) assuming comparable absorption for BM from both segments. Water soluble salt of BM was found to have faster rate of absorption relative to the BM but the extent of absorption was the same indicating that BM absorption is comparable throughout the intestine. ${ }^{25} \mathrm{BM}$ enema was compared to that of beclomethasone in treatment of distal inflammatory bowl disease. The former showed systemic side effects. In another study druginduced Cushing syndrome was reported for $\mathrm{BM}$ in patient with ulcerative colitis after administration of enema. ${ }^{26-27}$ These reports support our finding which suggested BM absorption from the lower parts of the intestine.

The mechanism of intestinal absorption of BM was studied as before by monitoring the relation between the absorptive clearance and the net water flux (Figure 6 and Table 3). The intercept was significantly different from zero in both segments $(\mathrm{P}<0.01)$. However, the slope of the regression line was not significantly different from zero again in both segments $(\mathrm{P}>0.05)$. This indicated predominant transcellular absorption with no dependence on the water flux. 

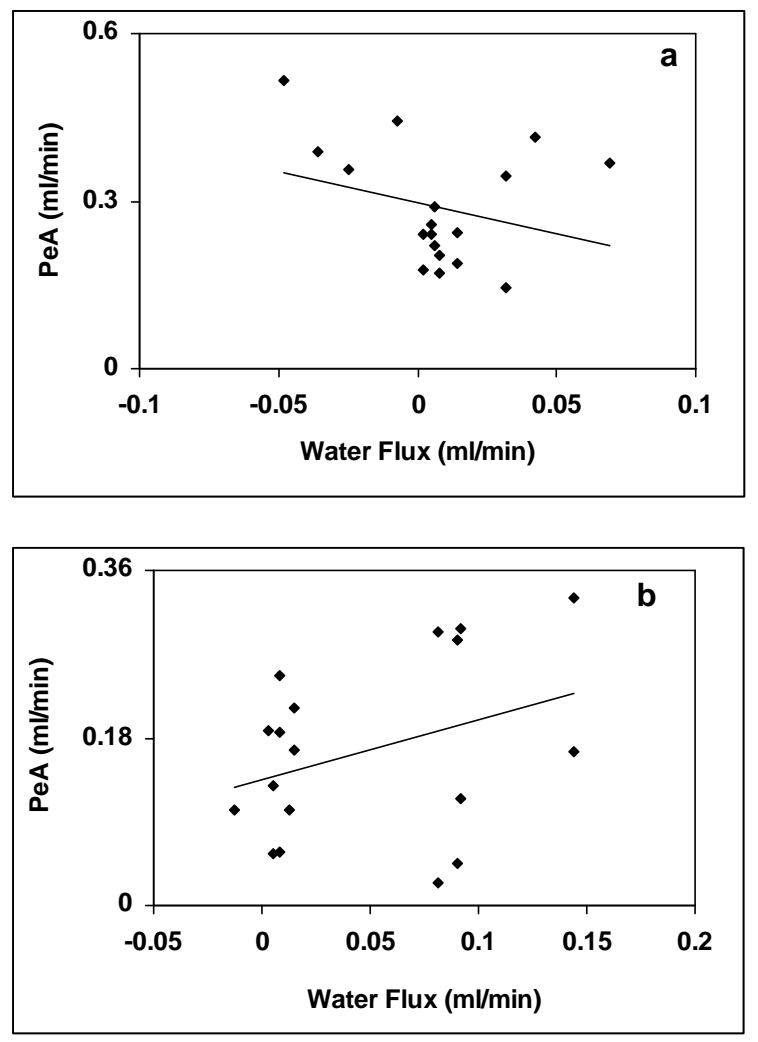

Fig. 6: Absorptive clearance versus water flux of betamethasone; (a) jejunoileum and (b) colon.

\section{Intestinal permeability of betamethasone valerate (BMV)}

Addition of an ester group to any drug is expected to increase the lipophilicity and reduce the PSA value of such drug. Accordingly, it should be expected that BMV should have lower PSA compared with the BM. Calculating the PSA for BMV however it was found 100.9 which is higher than that of BM. Also the $\log \mathrm{P}$ value was 3.6 for BMV which is greater than that of BM. BMV thus represent a unique case where introduction of an ester increased the two opposing factors (PSA and $\log \mathrm{P})$. The reason for this is that in the present case the $\mathrm{OH}$ group of $\mathrm{BM}$ was changed to an ester by reaction with valeric acid leading to addition of new carbonyl group to the structure together with the acyl chain.

The membrane-transport parameters of BMV though the jejunoileum (Table 1) reflected an almost complete absorption of BMV. The fraction absorbed was $97.46 \%$ and the fraction remaining for absorption was very small (0.0253). The L95\% was only 23.43 . The parameters derived for colonic absorption
(Table 2) revealed a very high absorption of BMV. The Fraction absorbed was $98.25 \%$ with only a very small fraction $(0.0175)$ remaining for absorption. A length of only $7.568 \mathrm{~cm}$ of the colon was required for $95 \%$ absorption.

Considering the segment length normalized absorptive clearance $(\mathrm{PeA} / \mathrm{L})$ the site dependent absorption was tested for BMV. The $\mathrm{PeA} / \mathrm{L}$ values were 0.0429 and 0.1279 $\mathrm{ml} / \mathrm{min} . \mathrm{cm}$, for the jejunoileum and colon respectively. The $\mathrm{PeA} / \mathrm{L}$ value was greater in the colon compared with that in the jejunoileum (Student`s $t$ test, $\mathrm{P}<0.001$ ). This is also against expectation for a non-polar drug like BMV.

The mechanism of intestinal absorption of BMV was monitored as before by analyzing the relation between the absorptive clearance and the net water flux (Figure 7 and Table 3). Like BM, the intercept was significantly different from zero in both segments $(\mathrm{P}<0.01)$. However, the slope of the regression line was not significantly different from zero again in both segments $(\mathrm{P}>0.05)$. This indicated predominant transcellular absorption with no dependence on the water flux.
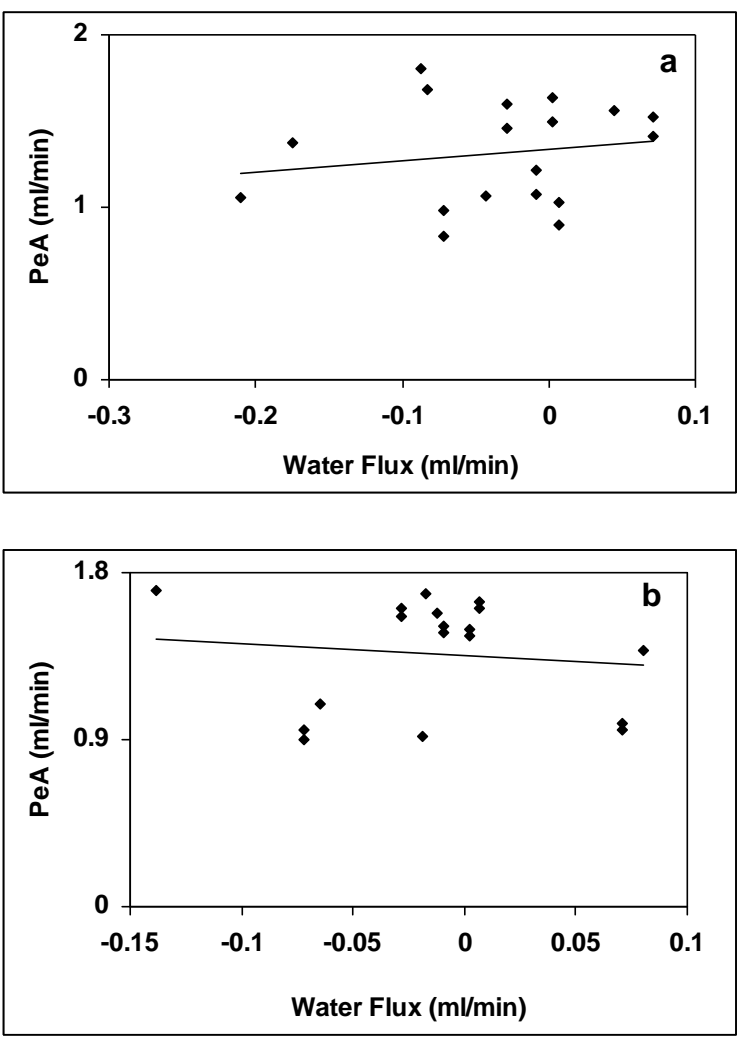

Fig. 7: Absorptive clearance versus water flux of betamethasone valerate; (a) jejunoileum and (b) colon. 


\section{Correlation of intestinal absorption with the PSA}

To correlate intestinal drug absorption with PSA the percentage fraction absorbed of drugs $(\% \mathrm{Fa})$ was plotted against the PSA. These plots produce the drug absorption PSA profile. This is graphically illustrated in Figure 8 for absorption from both the jejunoileum and the colon. Theoretically increasing the PSA should result in decreasing the intestinal absorption of drugs. In the present study increasing of PSA from $37.3 \AA$ to $91.67 \AA$ reduced the absorption from the jejunoileum. Any further increase in the PSA resulted in increased absorption again. This V-shaped profile is against theoretical expectations. This profile can be explained on the fact that the presence of florid in the structure of BM added more to the lipophilicity of the compound without any contribution in the PSA. This increase in lipophilicity masked the effect of the increase in PSA from to $91.67 \AA$ (PD) to $94.83 \AA$ (BM). In addition, we have a unique
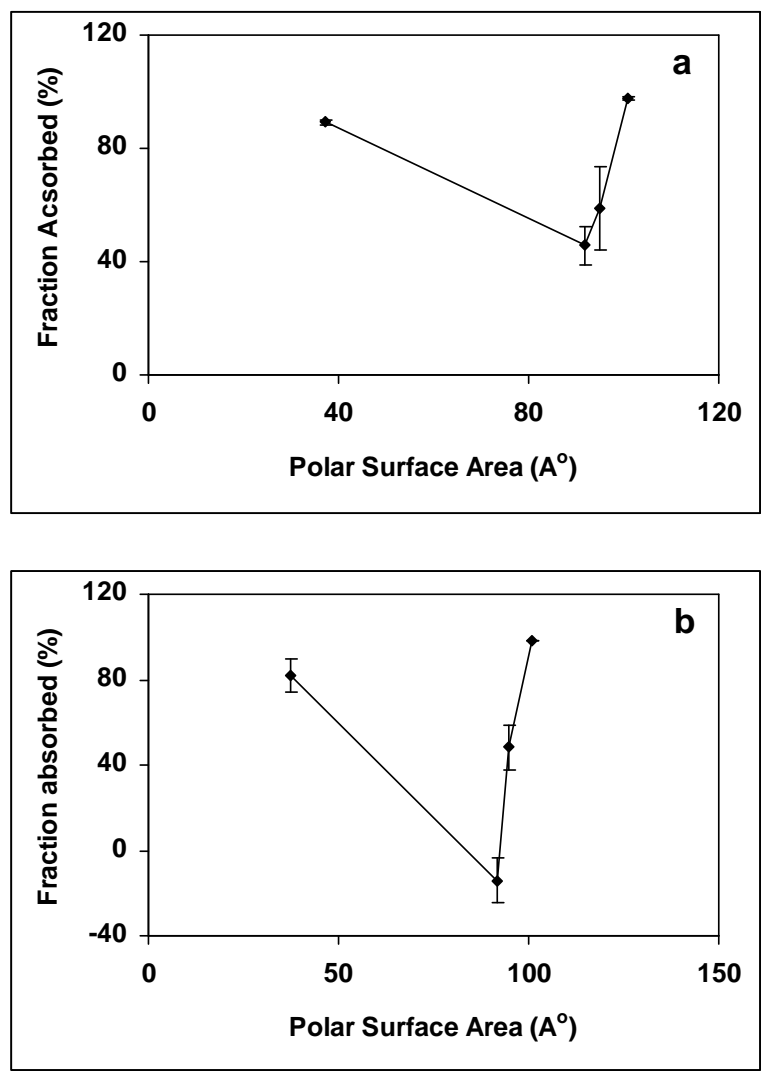

Fig. 8: Correlation of drug absorption from the jejunoileum (a) and the colon (b) with the polar surface area. case where the drug with the highest PSA value was found to be the most lipophilic. This was due to replacement of the hydroxyl group of BM with valeric acid ester group. This resulted in increasing the groups contributing to PSA by one carbonyl group thus the PSA increased from $94.83(\mathrm{BM})$ to 100.9 in case of BMV. However this increase was associated with great increase in the $\log \mathrm{P}$ (from 1.94 with $\mathrm{BM}$ to 3.6 with $\mathrm{BMV}$ ) due to the valerate acyl chain. This again masked the increase in PSA and resulted in further increase in intestinal absorption.

The absorption PSA profile from the colon (Figure 8b) was similar to that of the jejunoileum. This profile is against expectation for lipophilic drugs. These results suggested that PSA was unable to explain the recorded oral absorption results for the selected model drugs.

\section{Correlation of intestinal absorption with the octanol/warter partition coefficient}

The failure of PSA to explain the absorption results in the current study drew attention to use another factor for correlation. Accordingly, the intestinal absorption was correlated with the octanol/water partition coefficient (expressed as $\log \mathrm{P}$ ). The percentage fraction absorbed of drugs $(\% \mathrm{Fa})$ was plotted against $\log \mathrm{P}$. This is graphically illustrated in Figure 9 for absorption from both the jejunoileum and the colon. Figure 9 showed that increasing the $\log \mathrm{P}$ resulted in increase in the intestinal absorption of drugs. This direct relationship is expected for drug absorption from the jejunoileum segment but not expected for colonic absorption which is theoretically expected to depend on the water flux. Thus log $\mathrm{P}$ was able to explain the data obtained from jejunoileum but was not able to explain the obtained colonic absorption. 

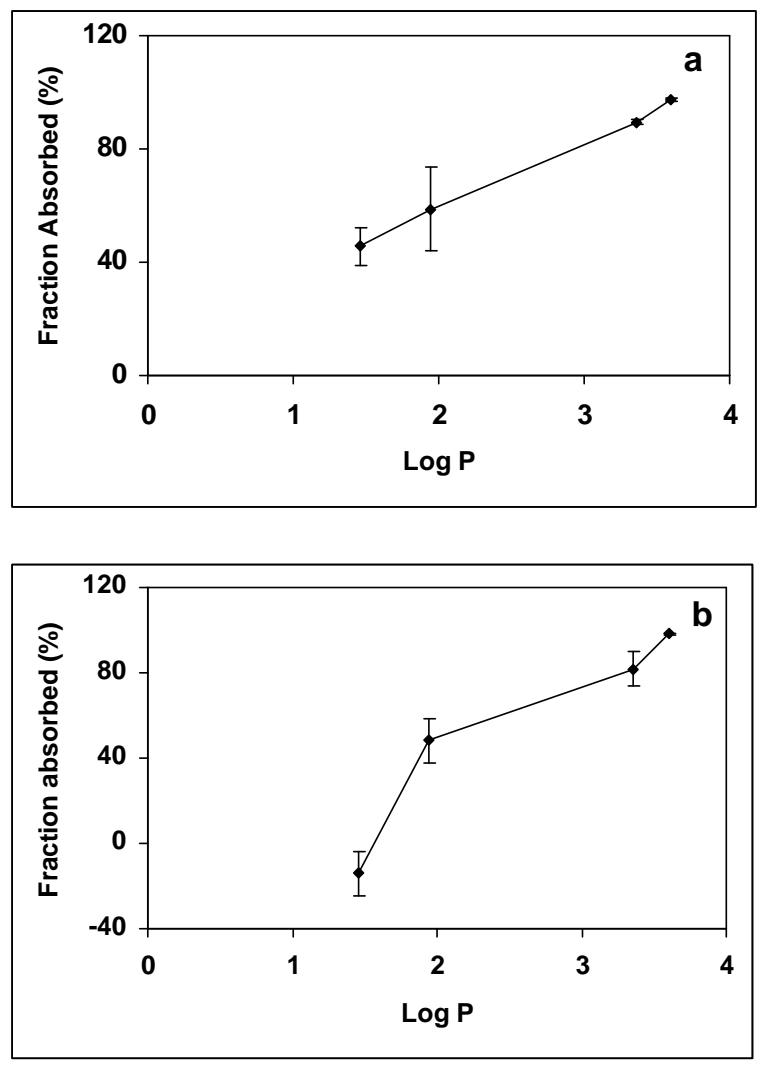

Fig. 9: Correlation of drug absorption from the jejunoileum (a) and the colon (b) with the octanol/water partition coefficient expressed as Log P.

\section{Conclusion}

1- PSA failed to account for intestinal absorption of the selected series of lipophilic steroids with respect to absorption from the jejunoileum and the colon.

2- The $\log \mathrm{P}$ value correlated with drug absorption from the jejunoileum but there was direct relationship between the colonic absorption and $\log \mathrm{P}$ which is against expectation.

3- Although the present study revealed failure for the PSA and some success for $\log \mathrm{P}$ as parameters predicting intestinal absorption of drugs, it is advisable not to rely on single factor as there will be always an exceptional case. Accordingly each factor should be used with caution and combination of factors will be useful.

\section{REFERENCES}

1- S. Winiwarter, F. Ax, H. Lennernas, A. Hallberg, C. Pettersson and A. Karlen, J. Mol. Graph. Model., 21 (4), 273-387 (2003).

2- R. Bartzatt and C. Malesa, Chemotherapy, 49 (5), 213-221 (2003).

3- A. Tronde, B. Norden, A. B. Jeppsson, P. Brunmark, E. Nilsson, H. Lennernas and U. H. Bengtsson, J. Drug Target., 11 (1), 61-74 (2003).

4- R. Bartzatt, J. Pharm. Pharmacol., 55 (5), 653-660 (2003).

5- X. C. Fu, C. X. Chen, W. Q. Liang, and Q. S. Yu, Acta Pharmacol. Sin., 22 (7), 663668 (2001).

6- A. Tronde, B. Norden, H. Marchner, A. K. Wendel, H. Lennernas and U. $H$. Bengtsson, J. Pharm. Sci., 92 (6), 12161233 (2003).

7- S. A. Kaplan, and M. L. Jack, "In vitro, in situ, and in vivo Models in Bioavailability Assessment" In: Blanchard J., R. J. Sawchuk and B. B. Brodie (Eds), "Principles and Perspectives in Drug Bioavailability", S. Karger, Basel, Switzerland, 1979, pp.156-191.

8- L. E. Riad and R. J. Sawchuk, Pharm. Res., 8 (8), 1050-1055 (1991).

9- J. P. Zhong, Y. F. Wang and R. J. Sawchuk, Pharm. Res., 9 (10), S, 350 (1992).

10- M. A. Osman, M. K. Youssef and R. J. Sawchuk, "In situ Absorption of the Antiviral Nucleoside Stavudine (D4T) from Rabbit Intestine", Alexandria Second International Conference of Pharmaceutical Sciences and Technology, Abstract book, 2000, p. 56.

11- C. A. Loehry, J. Kingham and J. Baker, Gut, 141, 683-688 (1973).

12- T. Maeda, H. Takenaka, Y. Yamahira and T. Noguchi, J. Pharm. Sci., 66 (1), 69-73 (1977).

13- D. N. Granger, P. R. Kvietys, M. A. Perry and J. A. Barrowman, "The Microcirculation and Intestinal Transport", In: L. R. Johnson (Ed), Physiology of the gastrointestinal tract, $2^{\text {nd }}$ edition, Raven Press, NY, Vol. 2, 1987, pp. 1671-1697. 
14- P. Ertl, B. Rhode and P. Selzer, J. Med. Chem., 43, 3714-3717 (2000).

15- G. E. Amidon, N. F. H. Ho, A. B. French and W. I. Higushi, J. Theo. Biol., 89, 195210 (1981).

16- I. Komiya, J. Y. Park, A. Kamani, N. F. H. Ho and W. I. Higuchi, Int. J. Pharm., 4, 249-262 (1980).

17- P. F. Ni, N. F. H. Ho, J. L. Fox, H. Leuenberger and W. I. Higuchi, Ibid., 5, 33-47 (1980).

18- N. F. H. Ho, H. P. Merkle and W. I. Higuchi, Drug. Dev. Ind. Pharm., 9 (7), 1111-184 (1983).

19- G. Gan, L. L. Cartier, Y. Huang, Z.Yang and R. J. Sawchuk, J. Pharm. Sci., 91 (1), 217-228 (2002).

20- F. A. A. Nunez and S. H. Yalkowsky, J. Pharm. Sci., 86 (10), 1187-1189 (2001).
21- A. M. Vick and W. L. Hayton, Aquat Toxicol., 52 (3-4), 177-188 (2001).

22- J. W. Georgitis, K. A. Flesher and S. J. Szefler, J. Allergy Clin. Immunol., 70 (4), 243-247 (1982).

23- C. Rollin, O. Chosidow, B. Diquet, C. Duteruil, S. Herson, J. Revuz and J. C. Delchier, Eur. J. Clin. Pharmacol., 44 (4), 395-399 (1993)

24- V. Grag, and W. J. Jusko, Biopharm. Drug Dipos., 15 (2), 163-172 (1994).

25- J. C. Loo, I. J. McGilveray, N. Jordan and R. Brein, Biopharm. Drug Dispos., 2 (3), 265-272 (1981).

26- Z. Halpern, O. Sold, M. Baratz, F. Konikoff, A. Halak and T. Gilat, J. Clin. Gastroenterol., 13 (1), 38-41 (1991).

27- S. Tsuruoka, K. Sugimoto and A. Fujimura, Drug Monit., 20 (4), 387-389 (1998). 